\title{
Catalyst-Substrate Effects on Biocompatible SABRE Hyperpolarization
}

\author{
Anand Manoharan, ${ }^{[a]}$ Peter J. Rayner, ${ }^{[a]}$ Marianna Fekete, ${ }^{[a]}$ Wissam lali, ${ }^{[a]}$ Philip Norcott, ${ }^{[a]}$ V. H. Perry \\ [b] and Simon B. Duckett ${ }^{*[a]}$
}

\begin{abstract}
The hyperpolarization technique, Signal Amplification by Reversible Exchange, has the potential to improve clinical diagnosis by making molecular magnetic resonance imaging in vivo a reality. Essential to this goal is the ability to produce a biocompatible bolus for administration. We seek here to determine how the identity of the catalyst and substrate affects the cytotoxicity by in vitro study, in addition to reporting how the use of biocompatible solvent mixtures influence the polarization transfer efficiency. By illustrating this across five catalysts and 8 substrates, we are able to identify routes to produce a bolus with minimal cytotoxic effects.
\end{abstract}

\section{Introduction}

Magnetic Resonance Imaging (MRI) is one of the principal techniques available to healthcare professionals around the world for the diagnosis of disease. MRI is widely used to give detailed structural images of the human body which can be reconstructed to give 3-dimensional information. It can also be applied to the study of neural activity in order to measure brain function. ${ }^{[1]}$ Unlike other diagnostic techniques, such as positron emission tomography (PET), ${ }^{[2]}$ it does not require ionizing radiation thereby allowing serial measurements to be made. However, the major limitation of MRI is its inherent low sensitivity which means that almost all applications to date detect a water signal due to its high concentration in the body. ${ }^{[3]}$

Classically, low signal strength has been overcome through the use of signal averaging over multiple repetitions or by increasing the magnetic field strength in which the measurements are made. Unfortunately, both of these methods result in cost and time penalties. Alternatively, the intra venous administration of paramagnetic agents, typically gadolinium ions, can improve MRI contrast through the modification of the water relaxivity profile. ${ }^{[4]}$ However, these agents are able to accumulate in the tissue and the subsequent onset of neurological, musculoskeletal, renal and dermal symptoms has been reported. ${ }^{[5]}$

The use of hyperpolarization methods, which turn the weak $\mathrm{MRI}$ responses into strong signals, has made safer high contrast

a] Dr. A. Manoharan, Dr. P. J. Rayner, Dr. M.Fekete, Dr. W. Iali, Dr. P. Norcott, Prof. S. B. Duckett

Department of Chemistry

University of York

Heslington

York

YO10 5DD (UK)

E-mail: simon.duckett@york.ac.uk

[b] Prof. V. H. Perry

School of Biological Sciences

University of Southampton

Southampton (UK)

Supporting information (SI) for this article is given via a link at the end of the document.
MRI a reality by perturbing the nuclear spin state level population away from Boltzmann distribution. They allow the study of molecular change within a human body to become possible. For example, Dynamic Nuclear Polarization (DNP) has been used to create the signal strength necessary to track the in vivo metabolism of pyruvate ${ }^{[6]}$ or glucose ${ }^{[7]}$ in tumors ${ }^{[8]}$ and whilst Spin Exchange Optical Pumping (SEOP) of noble gases has allowed the diagnosis of pulmonary diseases. ${ }^{[0]}$

The use of parahydrogen $\left(p-\mathrm{H}_{2}\right)$ as the source of polarization to give high sensitivity contrast agents has been the focus of much research over the recent decades. ${ }^{[10]}$ The latent magnetism in $p-\mathrm{H}_{2}$ is typically liberated through chemical addition to an unsaturated moiety such as a alkene or alkyne and has given access to ${ }^{13} \mathrm{C}$ MRI of atheroma in animal models. ${ }^{[11]}$ The main drawback of this technique is the requirement of the 'dehydro' precursor of the agent which would be detected, although recent studies have circumnavigated this through the use of cleavable molecular tags. ${ }^{[12]}$

An increasingly popular alternative, whereby the latent polarization of $p-\mathrm{H}_{2}$ is transfer to the target molecule without changing its chemical identity, is known as Signal Amplification by Reversible Exchange (SABRE). ${ }^{[13]}$ SABRE operates by the concurrent binding of $p-\mathrm{H}_{2}$ as hydride ligands and the target molecule to an iridium catalyst which allows the temporary formation of a scalar coupling network. ${ }^{[14]}$ The magnetic resonance active nuclei in the substrate (including $\left.{ }^{1} \mathrm{H},{ }^{[13 a}, 15\right]$ ${ }^{13} \mathrm{C},{ }^{[16]}{ }^{15} \mathrm{~N}^{[17]}$ and others ${ }^{[18]}$ ) become spontaneously polarized at low magnetic fields ${ }^{[19]}$ or by using r.f. methods in the observation field. ${ }^{[20]}$ Subsequent ligand exchange from the catalytic complex allows the build-up of hyperpolarized substrate in solution.

Initial SABRE experiments were performed using phosphine derived iridium complexes, ${ }^{[13 a]}$ however switching to $\mathrm{N}$ heterocyclic carbene (NHC) derivatives gave significantly improved performance. ${ }^{[21]}$ It has therefore become common to
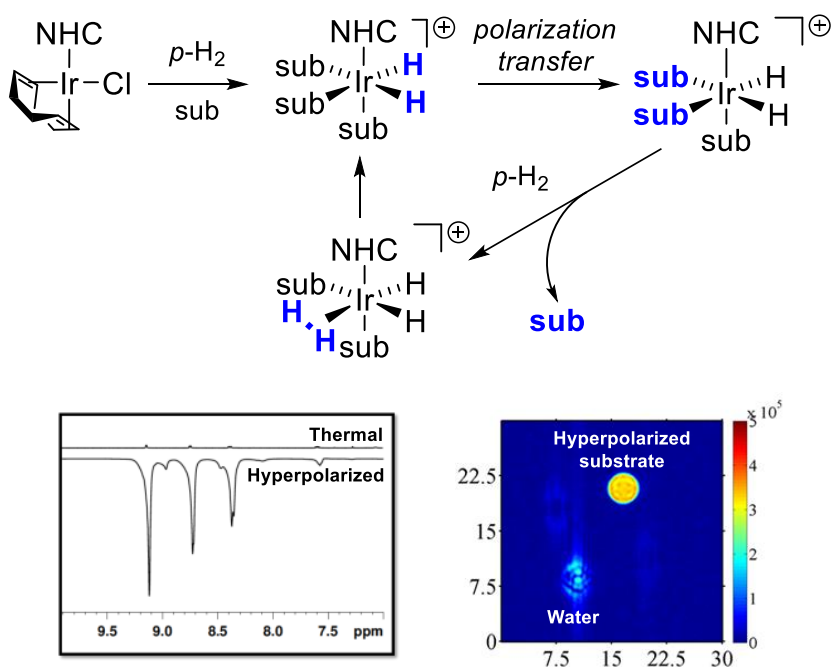

Detection by NMR or MRI techniques 
use a bench stable pre-catalyst of type $[\mathrm{IrCl}(\mathrm{COD})(\mathrm{NHC})](\mathrm{COD}=$ cis-cis-cycloocta-1,5-diene) and form the active SABRE catalyst by addition of excess $\mathrm{H}_{2}$ and substrate in solution. The identity of the $\mathrm{NHC}$ ligand has been probed ${ }^{[22]}$ and water soluble ${ }^{[23]}$ and heterogeneous ${ }^{[24]}$ alternatives have been introduced. Additionally, deuterated isotopologues have been reported to give improved signal enhancements and increased magnetic state lifetimes. ${ }^{[25]}$

As the SABRE technique progresses towards in vivo applications, the in vitro cytotoxicity of the reaction mixture has been investigated. ${ }^{[26]}$ In this study, a model SABRE formulation containing $[\mathrm{IrCl}(\mathrm{COD})(\mathrm{IMes})]$ (IMes = 1,3-bis $(2,4,6-$ trimethylphenyl)imidazol-2-ylidene), methyl 4,6- $d_{2}$-nicotinate $\left(\boldsymbol{d}_{2-}\right.$ $\mathbf{M N})^{[15]}$ in [D6]ethanol: $\mathrm{D}_{2} \mathrm{O}(30: 70)$ was employed and showed that neither the substrate nor the solvent induced cell death over $6 \mathrm{~h}$ exposure times. Conversely, the dominant factor in cell death was caused by the active SABRE catalyst, even at low concentration and exposure times. Importantly, this effect could be negated by removal of the catalyst using either catalyst deactivation and removal by ion exchange chromatography ${ }^{[26]}$ or bi-phasic catalysis. ${ }^{[27]}$ Additionally, catalyst capture using solid phase scavengers and subsequent filtration has proven an efficient method for catalyst depletion. ${ }^{[28]}$

We seek here to investigate how the effect of deuterating the SABRE catalyst influences the cytotoxicity. We achieve this through comparison of four isotopologues of the IMes ligand, as shown in Figure 1, whose SABRE performance for the hyperpolarization of methyl 4,6- $d_{2}$-nicotinate in biocompatible media and cytotoxicity are determined in parallel. The next step was to probe the effect of a caffeine derived SABRE catalyst which is soluble in aqueous solution. Finally the effect of changing the target substrate on the toxicity profile was quantified and determined to now arise from the result of an alternative active catalyst formation.

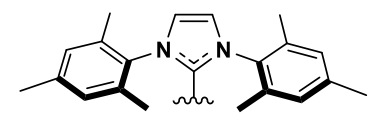

IMes
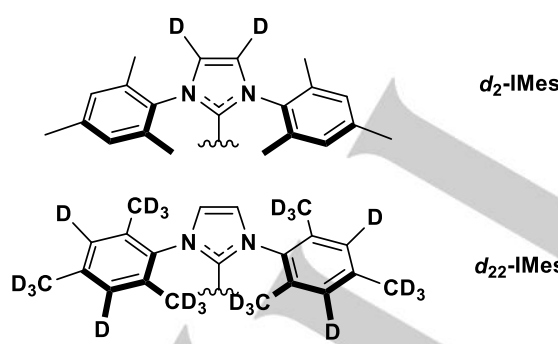

$d_{22}$-IMes

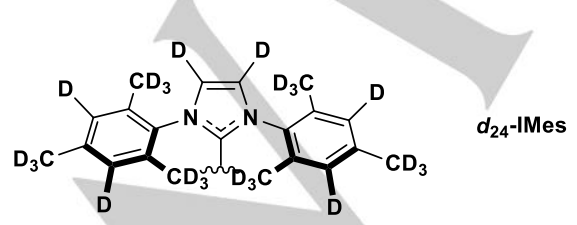

Figure 1. Isotopologues of the IMes ligand used in complexes of type $[\mathrm{IrCl}(\mathrm{COD})(\mathrm{NHC})]$ for SABRE catalysis

\section{Results and Discussion}

\section{Cytotoxicity of the catalyst isotopologues}

We began our study by investigating the effect that selective deuteration of the SABRE catalyst has on the cytotoxicity and polarization level in biocompatible media. This is essential for establishing the use of SABRE in biomedical applications. Therefore, we prepared a series of $5 \mathrm{mM}$ samples containing [IrCl(COD)(NHC)] (where NHC $=d_{2}$-IMes, $d_{22}$-IMes or $d_{24}$-IMes) and $20 \mathrm{mM}$ of $\boldsymbol{d}_{2}-\mathbf{M N}$ in $30 \%$ [D6] ethanol in $\mathrm{D}_{2} \mathrm{O}$ prior to exposure to $\mathrm{H}_{2}$ at a pressure of 3 bar. This led to the formation of the active SABRE catalyst in each case as determined by the presence of hydride signals in their ${ }^{1} \mathrm{H}$ NMR spectra. When the process was repeated with $p-\mathrm{H}_{2}$ and shaken in a $65 \mathrm{G}$ polarization transfer field at $298 \mathrm{~K}$, hyperpolarization was observed in the free $\boldsymbol{d}_{2}-\mathbf{M N}$ in solution. The total signal enhancements per proton were quantified to be 111,220 and 198 respectively for the catalysts bearing the $d_{2}$-IMes, $d_{22}$-IMes and $d_{24}$-IMes respectively. This trend is consistent with data reported for their respective polarization levels in non-aqueous solutions which was suggested to be due to reduced spin dilution and increased relaxation times upon deuteration. ${ }^{[25 b]}$ Both $d_{22}$-IMes and $d_{24}$-IMes showed significant improvements over protio-IMes which gave a 105-fold signal gain. ${ }^{[26]}$

Aliquots of these SABRE active solutions were then subjected to an appropriate cytotoxicity assessment method (MTT assay) on in vitro cultured human cell lines, namely A549 and MCF7. As such, various bolus volumes (1.25, 2.5, 5 and 10\%) of the SABRE reaction mixture were dosed onto the cell lines, alongside pure solvent ([D6]ethanol: $\left.\mathrm{D}_{2} \mathrm{O} 30: 70\right)$ and untreated cell controls. The MTT assay was then conducted for either short $(1 \mathrm{~h})$ or for long (6 and $24 \mathrm{~h}$ ) time periods.

As illustrated in Figure 2, treatment of A549 cells (or MCF7 cells, Supporting Information Figure S1) with the SABRE reaction mixture, that contained any of the deuterated catalyst isotopologues and $\boldsymbol{d}_{2}-\mathbf{M N}$, did not induce cytotoxicity at lower bolus volumes over short exposure times (1 h) (Figure $2 \mathrm{~A}$ and Supporting Information Figure S1 A). As expected, higher bolus volumes $(>2.5 \%$ ) contributed to toxicity over short exposure times. This is consistent with our previous report that used unlabeled $[\mathrm{IrCl}(\mathrm{COD})(\mathrm{IMes})]$ catalyst and $\boldsymbol{d}_{2}-\mathbf{M N} .^{[26]}$ As the treatment prolonged, we observed only a slight reduction in the rate of cell death when the fully deuterated $\left[\operatorname{IrCl}(\mathrm{COD})\left(d_{24}-\mathrm{IMes}\right)\right]$ catalyst is employed (Figure $2 \mathrm{~B}$ ). However, when the cells were exposed for over $6 \mathrm{~h}$ cell viability was reduced for all of the different catalysts used and thus, we conclude that isotopic labelling of the catalyst has little influence on the cytotoxicity outcome when $\mathbf{d}_{2-}$ MN is used as the substrate.

\section{Substrate effects on cytotoxicity and polarization transfer}

Our next goal was to determine the effect of the substrate on the cytotoxicity profile of the SABRE mixture. We therefore changed the $\boldsymbol{d}_{2}$-MN for $4,6-d_{2}$-nicotinamide $\left(\boldsymbol{d}_{2}\right.$-Nam) and conducted similar analysis. $\boldsymbol{d}_{2}$-Nam has previously been shown to give $4.1 \%$ ${ }^{1} \mathrm{H}$ polarisation using [IrCl(COD)(IMes)] in [D4]methanol under 3 bar $p-\mathrm{H}_{2}{ }^{[25 b]}$ Nicotinamide has been previously used for at high doses in humans ${ }^{[29]}$ whilst a more recent in vivo study of inherited mouse glaucoma showed potential neuroprotective effects. ${ }^{[30]}$ In this study, we prepared a sample containing [IrCl(COD)(IMes)] (5 $\mathrm{mM}), \boldsymbol{d}_{2}$-Nam (20 mM) in 30\% [D6]ethanol in $\mathrm{D}_{2} \mathrm{O}$ and exposed it 
A

B

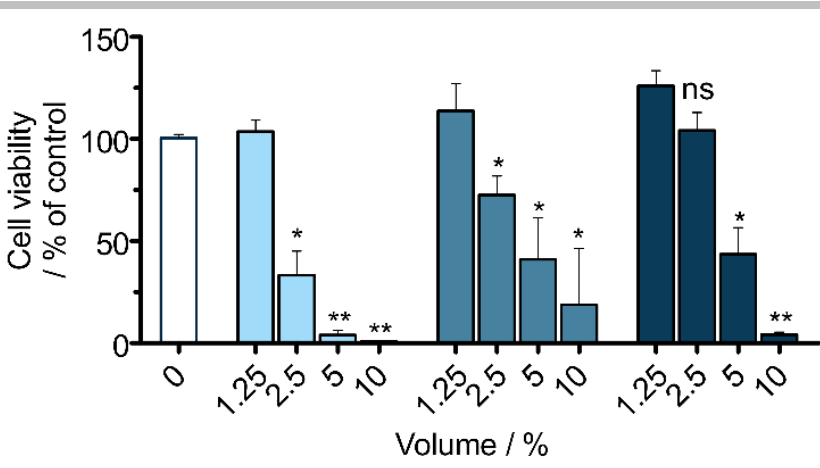

D

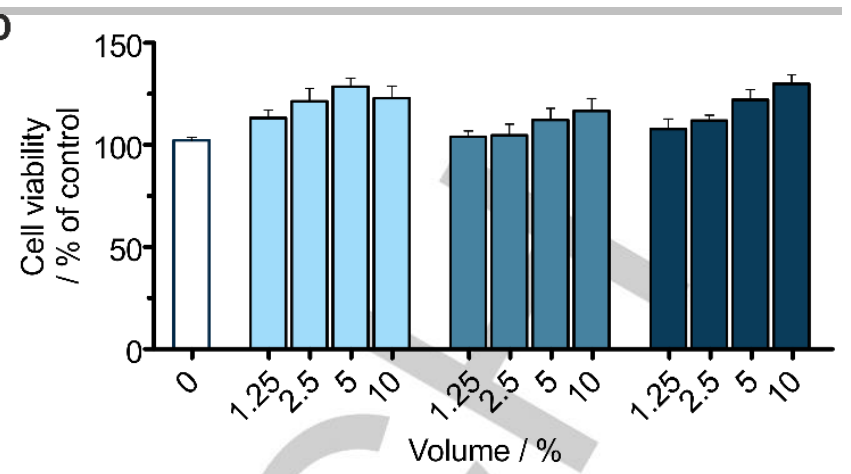

E

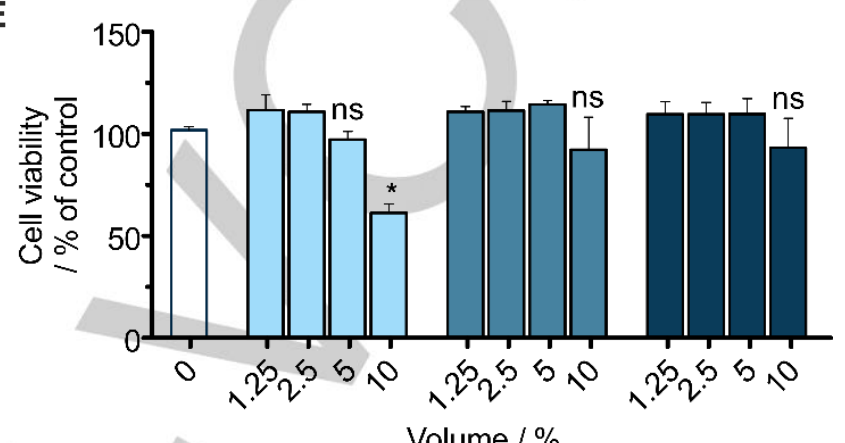

C
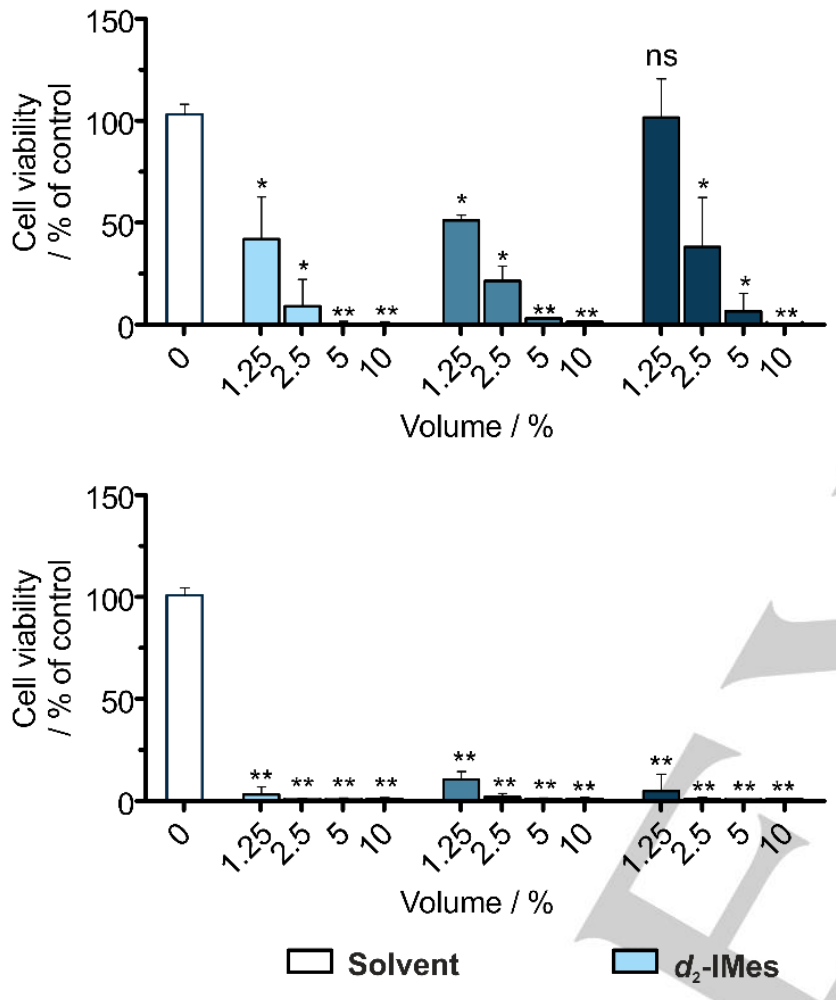

$\mathbf{F}$

Figure 2. Comparing cytotoxicity of deuterium labelled catalyst: MTT viability assay data showing A549 cells treated with SABRE reaction mixture containing $\boldsymbol{d}_{2}-\mathrm{MN}$ (left panel) or $\boldsymbol{d}_{\mathbf{2}}$-Nam (right panel) with the indicated catalysts. Treatments were carried out for $(A$ and $D) 1 \mathrm{~h}$, (B and $\mathrm{E}$ ) $6 \mathrm{~h}$ and $\left(\mathrm{C}\right.$ and F) $24 \mathrm{~h}$. Data are presented as mean $+\mathrm{SD}$ and are from 3 independent experiments $(\mathrm{n}=3) .{ }^{*} \mathrm{P}<0.05$, ${ }^{* *} \mathrm{P}<0.005$ and $\mathrm{ns}-\mathrm{Not}$ significant vs. the untreated control (100\% viable); one-way ANOVA.

to 3 bar $p-\mathrm{H}_{2}$ in a $65 \mathrm{G}$ polarization transfer field. The $\boldsymbol{d}_{2}-\mathrm{Nam}$ signal gain was quantified to be 102-fold however this was significantly increased by using the partially deuterated $\left[\operatorname{IrCl}(\mathrm{COD})\left(d_{22}\right.\right.$-IMes) $]$ catalyst which gave 606 -fold signal gain.

When $\boldsymbol{d}_{2}$-Nam was used as the substrate for the MTT assay under analogous conditions to that used with $\boldsymbol{d}_{2}-\mathbf{M N}$, survival of the cells changed dramatically. Now, cell viability was not altered at higher bolus volumes even when the treatment was prolonged to over $6 \mathrm{~h}$ in both the cell lines (Figure 2 for A549, see Supporting Information Figure S1 for MCF7 cells). This is surprising as $\boldsymbol{d}_{2-}$ Nam and $\boldsymbol{d}_{2}$-MN have comparable $\mathrm{IC}_{50}$ values (16.2 mM and 17.4 $\mathrm{mM}$ respectively for $\mathrm{A} 549$ cells, see Supporting Information Table $\mathrm{S} 1$ and reference ${ }^{[26]}$ ). Moreover, addition of $\boldsymbol{d}_{2}$-Nam dissolved in $30 \%$ [D6] ethanol in $\mathrm{D}_{2} \mathrm{O}$ alone to the cell culture medium did not reduce cell viability at concentrations higher than that is normally required for a SABRE reaction (Supporting Information Figure S2) Notably, when the cells were now exposed to the SABRE reaction mixture containing $\boldsymbol{d}_{2}$-Nam and any of the labelled catalysts, the viability of A549 cells was not reduced below $80 \%$ at bolus volumes $\geq 5 \%$ over $6 \mathrm{~h}$ (Figure $2 \mathrm{E}$ ) or below $50 \%$ at bolus volumes $\leq 2.5 \%$ over $24 \mathrm{~h}$ of exposure (Figure $2 \mathrm{~F}$ ). Similar effects on cell viability were observed when fully protio [ $\mathrm{IrCl}(\mathrm{COD})(\mathrm{IMes})]$ catalyst was used with $\boldsymbol{d}_{2}$-Nam (Supporting Information Figure S3).

These results allow us to draw two conclusions. First, isotopic labelling of the SABRE catalyst has little effect on the cytotoxicity of the SABRE reaction mixture to the two cell lines studied here. This allows the more potent isotopologues for SABRE polarization to be used without detriment to the biocompatibility of the bolus produced. Second, the cytotoxicity of SABRE mixture is dependent upon the substrate used. It is worth noting that when a substrate that has potential cyto-protective characteristics, such as nicotinamide used in this study, it is indeed possible to negate the cytotoxic potential of the catalyst. Additionally, while these results would in part envisage no requirement for removing the catalyst before use with biological materials, we do not propose a direct SABRE bolus for in vivo applications. This is due to the heavy metal exposure, which for 
iridium, the parenteral permitted daily exposure limit for humans is $10 \mu \mathrm{g} /$ day. ${ }^{[31]}$ If a nominal, $1 \mathrm{~g}$ dosage of the contrast agent is used, this equates to maximum $10 \mathrm{ppm}$ iridium concentration can be delivered in a single bolus. A number of methods for depleting the iridium content in solution have been reported, including biphasic catalysis, ${ }^{[27]}$ ion-exchange chromatography ${ }^{[26]}$ and solid phase scavengers. ${ }^{\text {[28a] }}$

With this in mind, we subjected the SABRE reaction mixture containing $\boldsymbol{d}_{2}$-Nam to deactivation with bathophenathroline disulfonic acid disodium (BPA) prior to depletion by ion-exchange chromatography to produce a biocompatible bolus with $\boldsymbol{d}_{2}$-Nam that contained $<1.7 \mathrm{ppm}$ of iridium by ICP-OES. This bolus also showed no long term cytotoxicity for exposure times of up to $24 \mathrm{~h}$ (Supporting Information Figure S4).

\section{Changing the identity of the catalyst}

The predominant catalysts used for SABRE catalyst are of type $[\mathrm{IrCl}(\mathrm{COD})(\mathrm{NHC})]$ due to their superior performance over phosphine derived alternatives. ${ }^{[21]}$ Our next goal was to determine whether the IMes derived systems were a contributing factor for the cytotoxicity of the SABRE reaction mixture. Our interest was in part provoked by the recent growth of metal-NHC based metallo-drugs, which is reflected in the number of reports that aimed to identify the anti-tumour properties of such drugs. ${ }^{[32]}$ Recent advances have used iridium as an alternate for platinum and ruthenium based systems. ${ }^{[33]}$ Therefore, we focused our attention on a range of $\mathrm{NHC}$ ligands that contain a xanthine core and have previously been noted for antimicrobial and anticancer activities. ${ }^{[34]}$ Xanthines are purine bases that are produced by both plants and animals and can be readily methylated. ${ }^{[35]}$ The natural methylated xanthines, theophylline, theobromine and caffeine (see Supporting Information Figure S5 for chemical structure) are present in tea, cocoa and coffee. They exhibit biologic activity as stimulants and have been used for therapeutic purposes. ${ }^{[36]}$

With this in mind, we synthesized a number of catalysts bearing these ligands (see Supporting Information for details on the synthesis and characterisation). The $[|r|(C O D)(\operatorname{tmx})]$ (where $\operatorname{tmx}=$ tetramethylxanthine, methylated caffeine) catalyst did not show high SABRE activity and the aqueous solubility was poor. In order to increase the water solubility and the level of signal enhancement we employed methylated 1,3,5-triaza-7phosphaadamantane (mPTA) as a co-ligand. ${ }^{[37]}$ Previous studies have shown that coordination of a phosphine co-ligand in the axial position of the active catalyst can improve its catalytic activity. ${ }^{[25 a]}$ On exposure of a solution containing $[\mid \mathrm{rl}(\mathrm{COD})(\mathrm{tmx})](5.5 \mathrm{mM})$, mPTA. $\mathrm{CF}_{3} \mathrm{SO}_{3}$ (1 eq.), Nam (4 eq.) in $30 \%$ [D6]ethanol in $\mathrm{D}_{2} \mathrm{O}$ to 3 bar $\mathrm{H}_{2}$ formation of $\left[\operatorname{Ir}(\mathrm{H})_{2}(\mathrm{Nam})(\right.$ solv $\left.)(\mathrm{mPTA})(\mathrm{tmx})\right](\mathrm{I})\left(\mathrm{CF}_{3} \mathrm{SO}_{3}\right)$ was observed (see Supporting Information for characterisation data). When the same was shaken under 3 bar $p-\mathrm{H}_{2}$ at $140 \mathrm{G}$, a resulting 37 -fold signal gain was observed which is significantly lower than the IMes derived systems.

Next, we wanted to test the effect of this caffeine derived catalyst on viability of cells cultured in vitro. For this, we took aliquots of the SABRE reaction mixture and added them to A549 and MCF7 cells in cell culture medium as described above. Our results show that at exposure times $\leq 6 \mathrm{~h}$ minimal cytotoxicity was observed over all bolus volumes for A549 cells (Figure 4). However, when the time was extended to $24 \mathrm{~h}$, cell death was seen at bolus volumes above $2.5 \%$. Again here it is not possible to exclude the cytotoxicity associated with the heavy metal

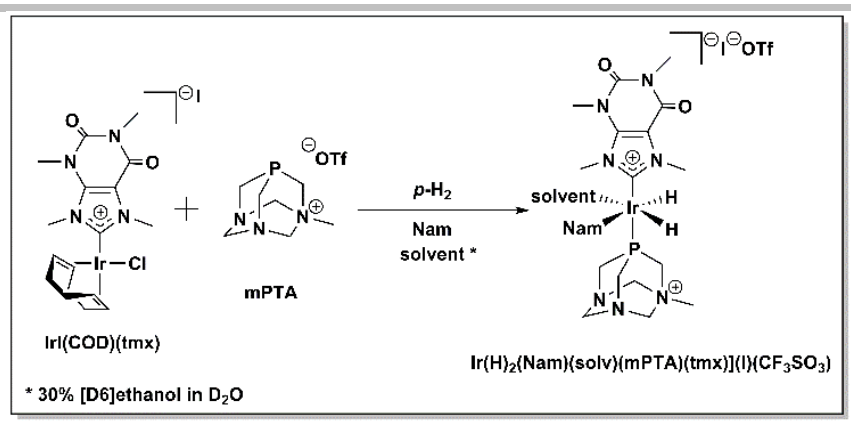

Figure 3. Conversion of $[\operatorname{lr}(\mathrm{COD})(\operatorname{tmx})$ to $\left[\operatorname{lr}(\mathrm{H})_{2}(\mathrm{Nam})(\mathrm{solv})(\mathrm{mPTA})(\mathrm{tmx})\right](\mathrm{I})\left(\mathrm{CF}_{3} \mathrm{SO}_{3}\right)$ by reaction with mPTA in the presence of $\mathrm{H}_{2}$ and $\mathrm{Nam}$.

contamination over long time exposure at higher doses. A similar trend was observed with MCF7 cells, however at exposure times of $6 \mathrm{~h}$ at bolus volumes $\geq 5 \%$ a reduction in cell viability was observed. From this we can conclude that modifying the ligands of the catalyst has minimal effect on cell viability when compared to IMes derived systems and therefore cell death may be arising due to metal contamination.

\section{Expansion to other biologically relevant target substrates}

Having shown that the ligand array on the catalyst has negligible effect on the resulting cytotoxicity of SABRE reaction mixture and instead the substrate's identity showed the dominant factor in cell survival, we wanted to examine a set of clinically relevant drugs. Therefore we began by selecting pyrazinamide (PZA) and isoniazid (INH) which are currently prescribed for the treatment of pulmonary disease, Tuberculosis (TB). PZA is a pyrazine derivative used in combination with other active ingredients to inhibit TB growth whilst INH, which is a pyridine derivative, has bactericidal properties against various Mycobacterium species. Both these compounds are prodrugs that become active in the infected body and have previously been shown to be polarized via SABRE with polarization levels of up to $6.1 \%$ and $2.1 \%$ in alcoholic solvents for PZA and INH respectively. ${ }^{[25 c, 38]}$

Whilst the pharmacological properties of both PZA and INH are well established, we wished to determine how interaction with the SABRE catalyst would affect the cytotoxicity profile. Hence, we prepared a series of samples containing $\left[\operatorname{IrCl}(\mathrm{COD})\left(d_{22}\right.\right.$-IMes)] (5 mM) and either PZA or INH (20 mM) in 30\% [D6]ethanol in $\mathrm{D}_{2} \mathrm{O}$ solution. $\left[\mathrm{IrCl}(\mathrm{COD})\left(d_{22}\right.\right.$-IMes)] was chosen as the catalyst due to previously showing optimal SABRE polarization levels and magnetic state lifetimes under the conditions used here. ${ }^{[25 c]}$ After exposure to $\mathrm{H}_{2}$ in order to form the active SABRE species, we conducted the MTT assay in analogous fashion to those prepared previously and the data is shown in Figure 5 .

When A549 cells were treated with the SABRE reaction mixture prepared with PZA or INH we found only a very low reduction in cell viability, even at doses of up to $10 \%$ bolus volume and over a $6 \mathrm{~h}$ exposure time. However, when the exposure times were extended to $24 \mathrm{~h}$, a reduction in cell viability was noted at higher bolus volumes, though $>50 \%$ viablity was maintained for all bolus volumes $\leq 2.5 \%$. We determined that the reduction in cell viability observed was likely to be due to the presence of the active SABRE catalyst because when using pure solutions of PZA or INH, no reduction in cell viability was recorded. Our results indicate that a set of drugs that are clinically prescribed for use in the treatment of human disease could be used for in vivo analysis by SABRE hyperpolarization. Additionally, since the activation of 
A

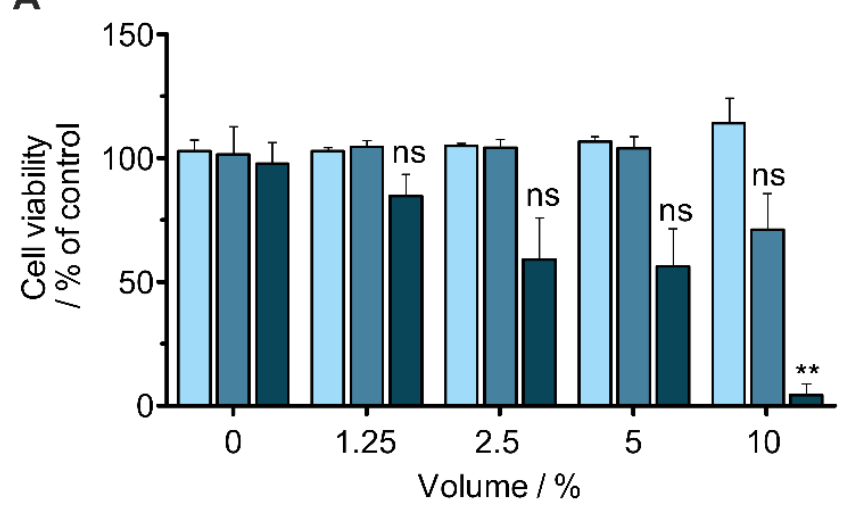

B

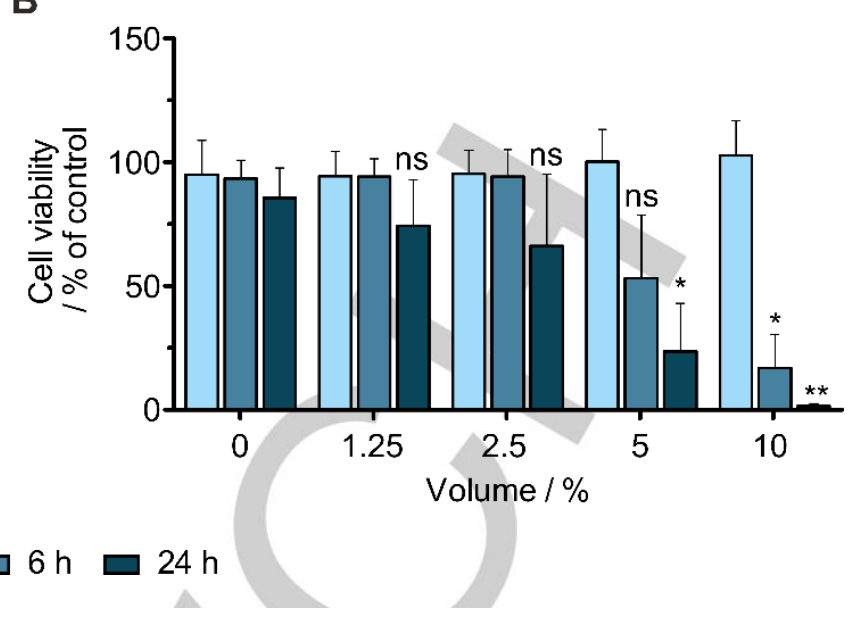

Figure 4. Evaluating cytotoxicity of water soluble catalyst: MTT cell viability assay data showing (A) A549 and (B) MCF7 cells treated with various bolus volumes of SABRE reaction mixture containing $\boldsymbol{d}_{2}$-Nam and $\left[\operatorname{lr}(\mathrm{H})_{2}(\operatorname{tmx})(\mathrm{mPTA})\right](\mathrm{I})\left(\mathrm{CF}_{3} \mathrm{SO}_{3}\right)$. Data are presented as mean $+\mathrm{SD}$ and are from 3 independent experiments $(n=3) .{ }^{*} \mathrm{P}<0.05,{ }^{* *} \mathrm{P}<0.005$ and $n s-$ Not significant vs. the untreated control group; one-way ANOVA.

the prodrug is dependent on the presence of the TB bacterium, these compounds might provide useful diagnostic information of the disease states in conjunction with real time MRI analysis.

The polarization of PZA and INH in 30\% [D6] ethanol in $\mathrm{D}_{2} \mathrm{O}$ was also studied using $\left[\mathrm{IrCl}(\mathrm{COD})\left(d_{22}\right.\right.$-IMes)] as the catalyst. Unfortunately, signal enhancements were only 10 and 16 -fold respectively under 3 bar $p-\mathrm{H}_{2}$ at $298 \mathrm{~K}$ and therefore prohibitively low for biomedical applications. It is noted that these signal gains are much lower than those reported in neat [D4]methanol solutions. ${ }^{[25 c, 38]}$ The partial deuteration of PZA and INH has previously been shown to improve polarization transfer while simultaneously extending their $T_{1}$ relaxation times in [D4]methanol and [D6]ethanol solution. ${ }^{25 c]}$ Therefore, we repeated the SABRE polarization experiments using the deuterated isotopologues. This caused an increase in signal gain for $\boldsymbol{d}$-PZA to 78 -fold and to 98 -fold for $\boldsymbol{d}_{2}$-INH. Additionally, this isotopic labelling strategy did not influence the outcome of the MTT assay for $\boldsymbol{d}$-PZA (Supporting Information Figure S7). When solubilized in $30 \%$ [D6]ethanol in $\mathrm{D}_{2} \mathrm{O}$, the treated $\mathrm{A} 549$ and MCF7 cells were $>50 \%$ viable at concentrations above what is normally required for SABRE. Importantly, cell viability obtained for $\boldsymbol{d}$-PZA is almost identical to that of the protio form PZA under SABRE reaction conditions (Figure 6) and indicates that deuterium labelling did not alter the way in which PZA is metabolized.

Finally, we further expanded the range of substrates to include methyl-5- $d$-pyrazinecarboxylate (5d-MePC), methyl-6- $d$ pyrazinecarboxylate $(\boldsymbol{6} d-\mathrm{MePC})$ and $2,5-d_{2}$-isonicotinamide $\left(\boldsymbol{d}_{2}-\right.$ iNam. SABRE samples were prepared with [IrCl(COD) $\left.\left(d_{22}-\mathrm{IMes}\right)\right]$ (5 mM) in $30 \%$ [D6]ethanol in $\mathrm{D}_{2} \mathrm{O}$ and exposed to 3 bar $p-\mathrm{H}_{2}$ in a $65 \mathrm{G}$ polarization transfer field. For $\mathbf{5} \boldsymbol{d}$-MePC, the total signal gain was quantified to be 182 -fold whereas $6 d$-MePC yielded signal gains of 1284 -fold at $9.4 \mathrm{~T}$. This equates to ca. $4 \%$ polarization and is the largest reported in this study and is comparable to that previously reported in pure [D6]ethanol solution. ${ }^{[25 c]} \boldsymbol{d}_{2}$-iNam also performed well under SABRE

A

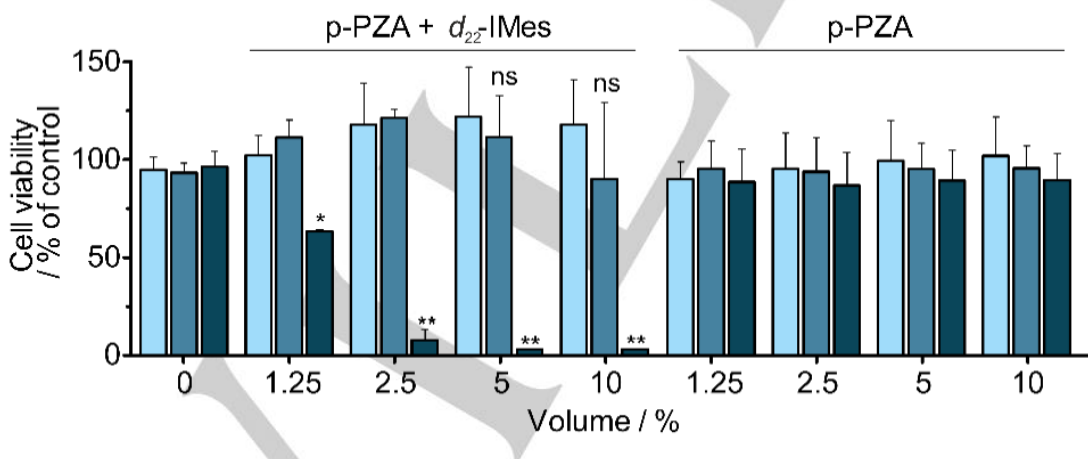

Figure 5. Cytotoxicity assessment of anti-TB drugs under SABRE: MTT viability assay data showing A549 cells treated with various volumes of protio forms ( $p$ ) of (A) PZA and (B) INH prepared under SABRE reaction conditions with or

B

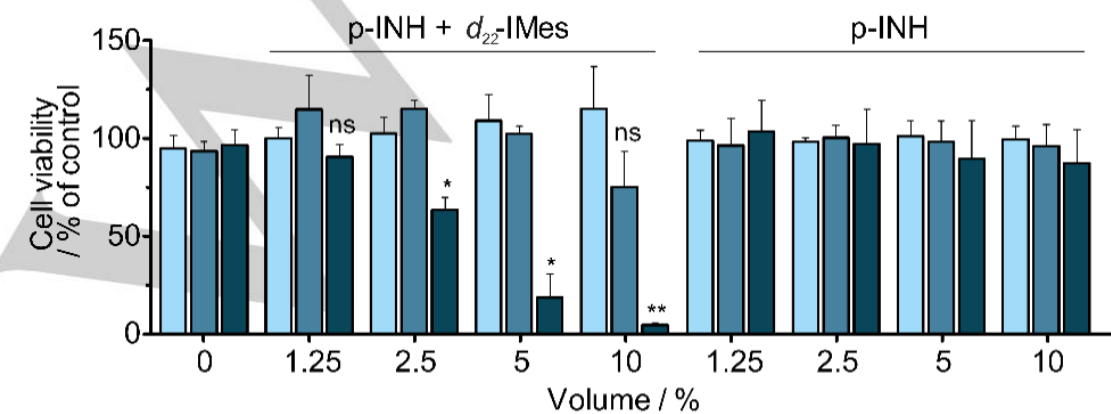
without the catalyst ( $d_{22}$-IMes). Data are presented as mean + SD and are from 3 independent experiments $(n=3)$. ${ }^{*} P<0.05$, ${ }^{* *} \mathrm{P}<0.005$ and $n s-$ Not significant vs. the untreated control group; one-way ANOVA. 
conditions and gave a 612-fold signal gain in the biocompatible solvent mixture.

We therefore exposed A549 cells to the SABRE mixtures containing $6 \boldsymbol{d}$-MePC and $\boldsymbol{d}_{2}$-iNam in order to determine their cytotoxicity profile. The results are depicted in Figure 6 . For exposure times $\leq 6 \mathrm{~h}$, no significant reduction in cell viability was observed for bolus volumes $\leq 2.5 \%$ when $6 d$-MePC was used as the substrate. However, at higher bolus volumes or longer exposure times cell death was seen. Conversely, $\boldsymbol{d}_{2}$-iNam showed no significant cell death for all bolus volumes studied for exposure times of up to $6 \mathrm{~h}$. On extending this time to $24 \mathrm{~h}$, cell survival was reduced at bolus volumes $\geq 5 \%$. Nevertheless, it would be expected that local exposure in vivo would be only for short time periods owing to the comparatively short life time of the polarization.

\section{Depleting iridium from final solution}

As a final iteration, we wished to quantify the residual metal content after the catalyst had been removed either by ion exchange chromatography ${ }^{[26]}$ or biphasic catalysis. ${ }^{[27]}$ First, two SABRE active samples containing [ $\mathrm{IrCl}(\mathrm{COD})(\mathrm{IMes})](5 \mathrm{~mm})$ and either MN or Nam were quenched by the addition of 1.1 eq. of bathophenanthroline sulfonic acid disodium as previously reported. ${ }^{[26]}$ Then, after ion exchange chromatography using DEAE Sephadex®, the solution was analyzed using ICP-OES. For the solution containing MN, 2.6 ppm of iridium was quantified in a $10 \%$ bolus volume whereas for Nam, $1.7 \mathrm{ppm}$ was detected. Alternatively, a biphasic sample containing [IrCl(COD)(IMes)] (5 mM) and either Nam or MN (20 mM, 4.0 eq.) in $\mathrm{CD}_{2} \mathrm{Cl}_{2}$ (dichloromethane - $\mathrm{DCM}$ ) and $\mathrm{D}_{2} \mathrm{O}$ (containing $0.9 \%$ $\mathrm{NaCl}$ ) gave rise to final iridium concentration of $0.6 \mathrm{ppm}$ when Nam was the substrate while the sample containing MN gave iridium concentrations below the detection limits $(0.1 \mathrm{ppm})$. This difference in iridium concentration between Nam and $\mathbf{M N}$ is likely to be due to the increase in water solubility of the active catalyst that is formed on reaction with Nam when compared to MN. This phenomenon has been previously harnessed to create water soluble SABRE polarization. ${ }^{[39]}$

Since biphasic SABRE catalysis method allows for rapid depletion of iridium, we further explored how alternative substrates affected the final iridium concentration and wanted to assess the effect of the aqueous fraction from the substrate $\boldsymbol{d}$ PZA prepared under biphasic SABRE mixture on cell viability. We expected to see similar cytotoxicity patterns as previously shown for the substrate $\boldsymbol{d}_{2}$-MN. First, analysis of the proton spectrum under thermal condition showed that $\boldsymbol{d}$-PZA is distributed between both aqueous and organic phase with a greater extent in aqueous solution (Figure $7 \mathrm{~A}$ ). Upon SABRE-derived biphasic catalysis, in the presence of $\mathrm{NaCl}$, hyperpolarisation of $\boldsymbol{d}$-PZA in aqueous phase occurs significantly higher (approx. 2000 fold) and the signal intensity remained for a longer time (over 2 mins) when compared to that of the $\boldsymbol{d}$-PZA in organic phase (Figure $7 \mathrm{~B}$ and Supporting Information Figure S10). SABRE hyperpolarisation of protio PZA was also notably similar under biphasic conditions (Supporting information Figure S11).

To assess the cytotoxicity of these reaction mixtures we then separated the aqueous phase and treated A549 and MCF7 cells with various volumes of the bolus. Consistent with the other substrates reported, cell viability was not altered even when very highest volume $(10 \%)$ of the aqueous solution derived from biphasic SABRE was added to the cell culture medium (Figure 8). Even over longer exposure times (24 h) of the aqueous fraction did not reduce the cell viability. Indeed, the viability profile matched that of $\boldsymbol{d}$-PZA alone under control conditions (Supporting Information Figure S12) which clearly indicated that the toxicity is negated by the exclusion of the catalyst that is retained in the organic phase. Also, when the other anti-TB drug, INH, was studied in an analogous fashion, the cytotoxicity followed similar patterns with almost no adverse effect on in vitro cultured cells when treated with catalyst free solutions prepared by biphasic SABRE (Supporting Information Figure S13). These results clearly demonstrated that clinically relevant target substrates can be further utilized for in vivo imaging by MRI when biphasic SABRE method is employed.

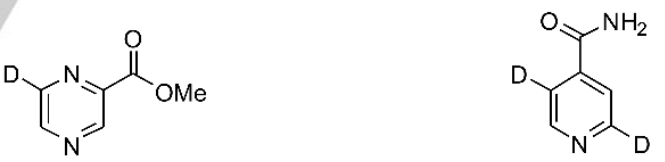

$6 d-\mathrm{MePC}$ $d_{2}-\mathrm{iNam}$

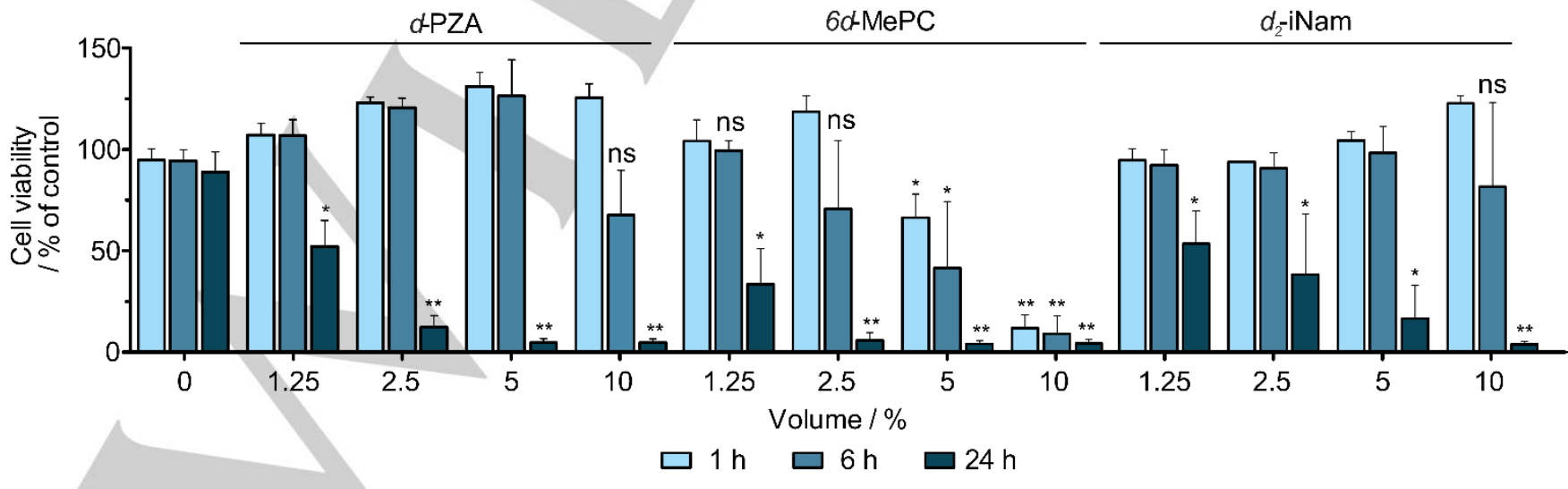

Figure 6. Effect of deuterium labelling on cell viability: MTT assay data showing A549 cells treated with various volumes of the SABRE reaction mixture containing $d_{22}$-IMes and deuterium labelled target substrates $\boldsymbol{d}$-PZA or $\mathbf{6} \boldsymbol{d}$-MePC or $\boldsymbol{d}_{2}$-iNam. Data are presented as mean + SD and are from 3 independent experiments $(n=3) .{ }^{*} P<0.05,{ }^{* *} P<0.005$ and $n s$ - Not significant vs. the untreated control group; one-way ANOVA. 
A

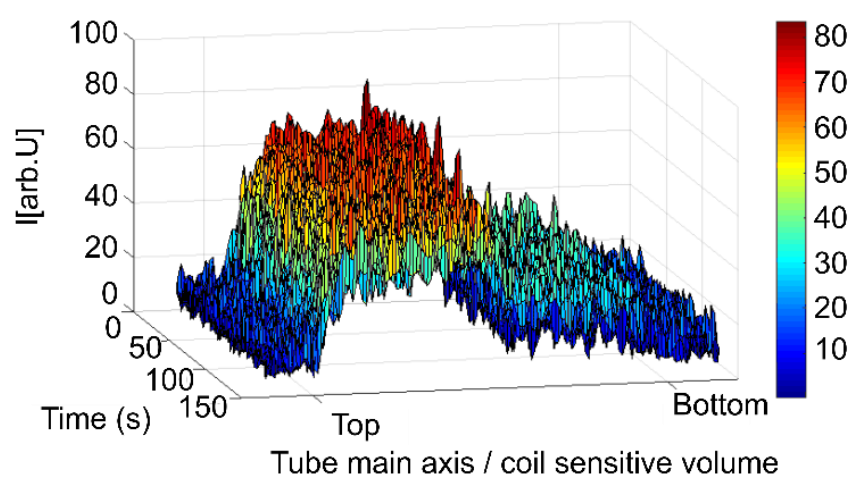

B

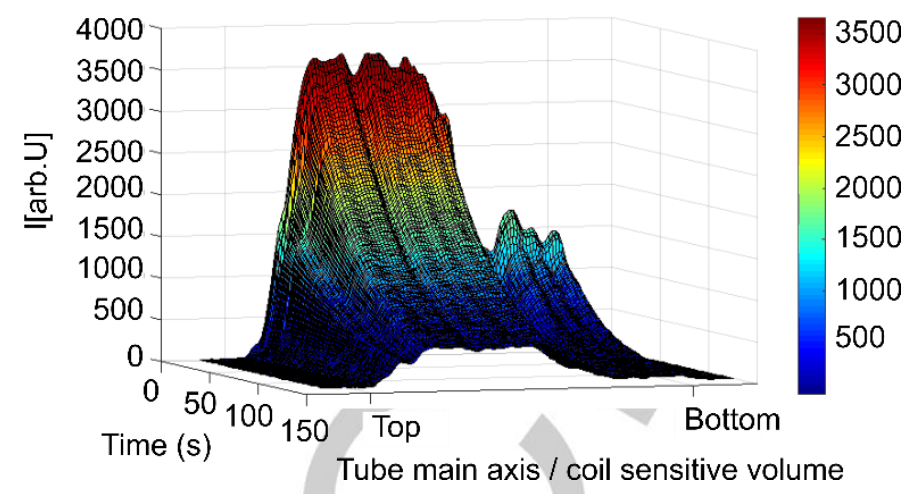

Figure 7. Biphasic SABRE using $\boldsymbol{d}$-PZA: The ${ }^{1} \mathrm{H}$ NMR signal intensity of a biphasic solution of $\left[\mathrm{IrCl}(\mathrm{COD})\left(d_{22}-\mathrm{IMes}\right)\right](5 \mathrm{mM})$ and $\boldsymbol{d}-\mathrm{PZA}(20 \mathrm{mM})$ in $\mathrm{CD}{ }_{2} \mathrm{Cl}_{2}(1.5$ $\mathrm{mL})$ and $\mathrm{D}_{2} \mathrm{O}(1.5 \mathrm{~mL}, 0.9 \% \mathrm{NaCl})$ as a function of distance from the bottom of the NMR tube at (A) thermal and (B) SABRE hyperpolarised conditions. Top aqueous phase; Bottom - organic phase (see Supporting Information for further details).

A

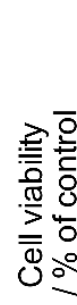

150
B

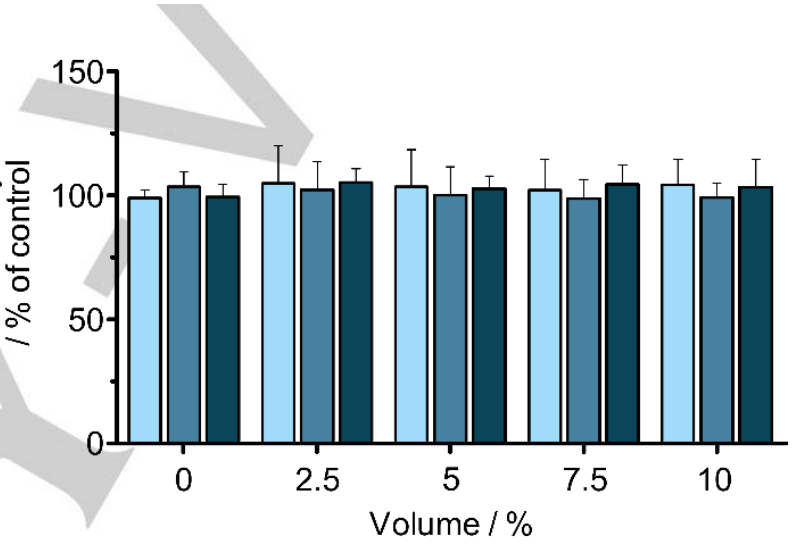

$6 \mathrm{~h}$

$24 \mathrm{~h}$

Figure 8. Biocompatibility achieved by Biphasic SABRE: MTT cell viability assay on (A) A549 and (B) MCF7 cells treated with various volumes of aqueous phase separated from biphasic SABRE reaction mixture that contained $\boldsymbol{d}$-PZA. Data are presented as mean $+\mathrm{SD}$ and are from 3 independent experiments ( $\mathrm{n}=3$ ). ${ }^{\star} \mathrm{P}<0.05,{ }^{* \star} \mathrm{P}<0.005$ and $\mathrm{ns}-$ Not significant vs. the untreated control group; one-way ANOVA.

\section{Conclusions}

The ability to produce a biocompatible SABRE hyperpolarized bolus or in vivo administration is a key step in advancing the technique toward clinical applications. In this study, we have shown that changing the ligand on the SABRE catalyst does not have a significant influence on the resulting cytotoxicity. When the MTT assay was conducted on the SABRE reaction mixture containing deuterated isotopologues, $d_{2}$-IMes, $d_{22}$-IMes or $d_{24-}$ IMes, in conjunction with $d_{2}-\mathrm{MN}$, no increase in cell death was observed when compared to the protio form. Indeed, at bolus volumes $<2.5 \%$, a significant reduction in cell viability was shown even over short time periods. However, these effects can be negated by removing the iridium catalyst by either ion exchange chromatography or biphasic catalysis. These methods render a biocompatible bolus with $<2 \mathrm{ppm}$ iridium content by ICP-OES. Moreover, the SABRE induced signal gains improved from 100fold when using the IMes derived catalyst to over 200 -fold when $d_{22}$-IMes was employed in $30 \%$ [D6] ethanol in $\mathrm{D}_{2} \mathrm{O}$.

Interestingly, when the substrate was changed to nicotinamide and its isotopically labelled derivate 4,6- $d_{2}-$ nicotinamide the cytotoxicity of the SABRE reaction mixture was negated; even at high bolus volumes and long exposure times. We suggest that this could be due to the potential cyto-protective features of nicotinamide. Despite limited cell death being observed with this substrate, we would not envisage in vivo administration of the SABRE reaction mixture without first reducing the iridium content to below recommended exposure limits. ${ }^{[31]}$ When $\left[\mathrm{IrCl}(\mathrm{COD})\left(d_{22}\right.\right.$-IMes)] was used as the catalyst, exposing the sample containing $\boldsymbol{d}_{2}$-Nam to $p-\mathrm{H}_{2}$ in a $65 \mathrm{G}$ polarization transfer field gave a 606 -fold signal gain in the biocompatible solvent mixture. Replacing the IMes ligand with a caffeine derivative, the cyctoxicity profile did not change. Therefore, we conclude that the ligand identity has minimal effect and that the cytoxicity is resulting from residual heavy metal content. This catalyst, despite its improved aqueous solubility, gave reduced signal enhancements with nicotinamide.

By expanding the range of substrates to include tuberculosis drugs, such as isoniazid and pyrazinamide, we have exemplified a route to produce a biocompatible hyperpolarized bolus of a clinically prescribed product. This may lead to the potential to monitor the drugs uptake and metabolism by in vivo MRI. In both cases, cell death was observed for the SABRE reaction mixture over $24 \mathrm{~h}$ exposure times although at low bolus volumes and shorter exposure times cell survival improved. This cytotoxicity was shown to be derived from the presence of the 
iridium catalyst and could be removed by catalyst elimination. In fact, when using biphasic SABRE catalysis with $\boldsymbol{d}$-PZA a signal enhancement of up to 2000-fold was observed with a signal that survived for over 2 minutes. These data show that the toxicity assessment of each target substrate would be required prior to in vivo administration however the predominant cytotoxic feature is due to the presence of the iridium catalyst.

Currently, all catalyst sequestering techniques introduce additional variables and time implications to the SABRE technique. These may be associated with the addition of chelating agents, solid phase scavengers or solvent separation. Additionally, we note that the signal enhancements quantified in $30 \%\left[D_{6}\right]$ ethanol in $D_{2} \mathrm{O}$ are significantly lower than those achieved in organic solvents such as ethanol. We suggest that larger polarization levels could be accomplished by conducting the polarization in $100 \%\left[D_{6}\right]$ ethanol with subsequent dilution with $\mathrm{D}_{2} \mathrm{O}$. Therefore we are working towards the goal of creating an automated system to provide a reliable route to a delivering SABRE hyperpolarized and catalyst free bolus for clinical use.

\section{Experimental Section}

\section{Chemicals and reagents}

All chemicals were purchased from Sigma-Aldrich, Fisher or Alfa-Aesar. Deuterated solvents ([D6]ethanol, deuterium oxide $\left(\mathrm{D}_{2} \mathrm{O}\right)$ and dichloromethane (DCM) were purchased from Sigma. The following compounds were prepared according to literature procedures:methyl 4,6$d_{2}$ nicotinate, ${ }^{[25 \mathrm{~b}]} 4,6-d_{2}$-nicotinamide, ${ }^{[25 \mathrm{~b}]}$ methyl-5- $d$-pyrazinecarboxylate, methyl-6- $d$-pyrazinecarboxylate, $\quad 2,5-d_{2}$-isonicotinamide, ${ }^{[25 b]} 6$ - $d$ pyrazinamide, 2,5- $d_{2}$-isonaizid, $\quad[\operatorname{IrCl}(\mathrm{COD})(\mathrm{IMes})]^{[40]} \quad[\operatorname{IrClCOD})\left(\mathrm{d}_{2}-\right.$ IMes)], $\left.{ }^{[25 b]}[\mathrm{IrClCOD})\left(\mathrm{d}_{22}-\mathrm{IMes}\right)\right]^{[25 \mathrm{~b}]}$ and [IrCICOD $\left.)\left(\mathrm{d}_{24}-\mathrm{IMes}\right)\right] .^{[25 \mathrm{~b}]}$

\section{Cell culture and treatment}

A549 and MCF7 cells were grown in DMEM supplemented with $10 \%$ fetal bovine serum (FBS), penicillin $(100 \mathrm{U} / \mathrm{ml})$, streptomycin $(100 \mu \mathrm{g} / \mathrm{ml})$ and L-Glutamine (2mm) (all from Gibco, Life Technologies). The cells were maintained in a humidified atmosphere under standard conditions $\left(37^{\circ} \mathrm{C}\right.$ $5 \% \mathrm{CO}_{2}$ ). For treating cells with SABRE reaction mixture we followed the same method as illustrated previously ${ }^{[26]}$. Before treatment various volumes of the SABRE reaction mixture were diluted to a maximum of 10 $\mu \mathrm{l}$ in the same solvent from which the compounds were originally prepared. The final volume of the solvent or reaction mixture was always kept as $10 \%$ in the total volume of the cell growth medium (i.e. $10 \mu \mathrm{l}$ in $100 \mu \mathrm{l}$ ).

Cell viability assay by MTT method

Viability of the cells post treatment with various reaction mixtures were carried out by MTT method ${ }^{[41]}$. In this method, the reduction of tetrazolium to insoluble formazan crystals by the active mitochondrial dehydrogenase in living cells allows to quantify cell viability. For this assay, cells (normally $10^{4}$ cells per well in a 96-well plate) were taken in triplicates and treated with the compound dissolved in solvent or without the compounds (solvent alone or untreated controls) in cell growth media. After incubation, at a desired time point the cell growth media was replaced with fresh media $(100 \mu \mathrm{l})$ and incubated with $10 \mu \mathrm{l}$ of MTT $(5 \mathrm{mg} / \mathrm{ml}$, dissolved in cell growth media and filter $(0.22 \mu \mathrm{m})$ sterilized) for a further $4 \mathrm{~h}$ at $37^{\circ} \mathrm{C}$. The medium with MTT was then carefully aspirated and the resulting formazan crystals were solubilized in $100 \mu \mathrm{l}$ of Dimethyl sulfoxide (DMSO). The absorbance was then measured at $570 \mathrm{~nm}$ using a microplate reader (MultiskanGO, Thermofisher). The absorbance of a series of cells that were exposed to the cell growth medium only was taken as $100 \%$ viable (i.e. the untreated control sample). The cell viability of the compound treated samples were then calculated by normalising to the untreated control sample and are expressed as \% of control. For statistical analysis of the data each assay was repeated a minimum of three times.

\section{SABRE Hyperpolarization}

SABRE polarization using $[\operatorname{IrCl}(\mathrm{COD})(\mathrm{NHC})]$ in $30 \%$ [D6]ethanol in $\mathrm{D}_{2} \mathrm{O}$ solution: A $5 \mathrm{~mm}$ J. Young's tap NMR tube containing a $5 \mathrm{~mm}$ (unless otherwise stated) solution of $[\mathrm{IrCl}(\mathrm{COD})(\mathrm{NHC})](5 \mathrm{mM})$ and substrate (4 eq.) in $30 \%$ [D6]ethanol in $\mathrm{D}_{2} \mathrm{O}(0.6 \mathrm{~mL})$ was degassed prior to the introduction of $\mathrm{H}_{2}$. Samples were left to form the active catalyst for $1 \mathrm{~h}$ prior to the replacement of $\mathrm{H}_{2}$ with $p-\mathrm{H}_{2}$. The samples were then shaken for 10 $s$ in the specified fringe field of an NMR spectrometer for polarization transfer before being rapidly transported into the magnet for subsequent interrogation by NMR spectroscopy.

SABRE polarization using $\left[\operatorname{lr}(\mathrm{H})_{2}(\mathrm{Nam})(\right.$ solv $\left.)(\mathrm{tmx})(\mathrm{mPTA})\right](\mathrm{I})\left(\mathrm{CF}_{3} \mathrm{SO}_{3}\right)$ in $30 \%$ [D6]ethanol in $\mathrm{D}_{2} \mathrm{O}$ solution:

Biphasic catalysis method

A solution of $\left[\mathrm{IrCl}(\mathrm{COD})\left(d_{22}-\mathrm{IMes}\right)\right](5 \mathrm{mM})$ and $\boldsymbol{d}$-PZA or other substrates indicated in the text (20 mM, 4 eq.) in $\mathrm{DCM}(1.5 \mathrm{~mL})$ and $\mathrm{D}_{2} \mathrm{O}$ (containing $0.9 \% \mathrm{NaCl})(1.5 \mathrm{ml})$ was mixed together and degassed prior to the introduction of hydrogen at a pressure of 3 bar. When the two fractions (aqueous and organic) separate, aqueous solution was carefully taken out and various volumes were used for treatment on cells. Further dilutions were made to a maximum of $10 \mu \mathrm{l}$ in the same solvent.

Statistical analysis

All experiments were performed at least three times $(n=3)$ and all data is presented as mean and standard deviation (SD) of the mean. Statistical significance was set at $P$ values $<0.05$.

\section{Acknowledgements}

The Wellcome Trust (092506 and 098335) are thanked for funding. We thank Gary Green and all present and former members of $\mathrm{CHyM}$ for scientific discussions.

\section{Conflict of interest}

The authors declare no conflict of interest.

Keywords: Hyperpolarization - SABRE - Biocompatibility • Biomolecules • Cytotoxicity

[1] K. K. Kwong, J. W. Belliveau, D. A. Chesler, I. E. Goldberg, R. M. Weisskoff, B. P. Poncelet, D. N. Kennedy, B. E. Hoppel, M. S. Cohen, R Turner, et al., Proc Natl Acad Sci U S A 1992, 89, 5675-5679.

[2] M. M. Ter-Pogossian, M. E. Phelps, E. J. Hoffman, N. A. Mullani, Radiology 1975, 114, 89-98.

[3] F. A. Gallagher, Clin Radiol 2010, 65, 557-566.

[4] P. Caravan, J. J. Ellison, T. J. McMurry, R. B. Lauffer, Chemical Reviews 1999, 99, 2293-2352.

[5] M. Rogosnitzky, S. Branch, Biometals 2016, 29, 365-376.

[6] H. Gutte, A. E. Hansen, H. H. Johannesen, A. E. Clemmensen, J. H. Ardenkjar-Larsen, C. H. Nielsen, A. Kjar, American journal of nuclear medicine and molecular imaging 2015, 5, 548-560

[7] T. B. Rodrigues, E. M. Serrao, B. W. C. Kennedy, D.-E. Hu, M. Kettunen, K. M. Brindle, Nature Medicine 2013, 20, 93 
[8] J. Kurhanewicz, D. B. Vigneron, K. Brindle, E. Y. Chekmenev, A Comment, C. H. Cunningham, R. J. DeBerardinis, G. G. Green, M. O Leach, S. S. Rajan, R. R. Rizi, B. D. Ross, W. S. Warren, C. R. Malloy, Neoplasia 2011, 13, 81-97.

[9] (a) P. Nikolaou, A. M. Coffey, L. L. Walkup, B. M. Gust, N. Whiting, H. Newton, S. Barcus, I. Muradyan, M. Dabaghyan, G. D. Moroz, M. S Rosen, S. Patz, M. J. Barlow, E. Y. Chekmenev, B. M. Goodson, Proceedings of the National Academy of Sciences of the United States of America 2013, 110, 14150-14155; (b) P. Nikolaou, A. M. Coffey, L. L. Walkup, B. M. Gust, N. Whiting, H. Newton, I. Muradyan, M. Dabaghyan, K. Ranta, G. D. Moroz, M. S. Rosen, S. Patz, M. J. Barlow, E. Y Chekmenev, B. M. Goodson, Magnetic Resonance Imaging 2014, 32, 541-550.

[10] S. B. Duckett, R. E. Mewis, Acc Chem Res 2012, 45, 1247-1257.

[11] P. Bhattacharya, E. Y. Chekmenev, W. F. Reynolds, S. R. Wagner, N. Zacharias, H. R. Chan, R. Bünger, B. D. Ross, NMR in Biomedicine 2011 24, 1023-1028.

[12] (a) F. Reineri, T. Boi, S. Aime, Nature Communications 2015, 6, 5858; (b) E. Cavallari, C. Carrera, S. Aime, F. Reineri, Chemistry-A European Journal 2017, 23, 1200-1204.

[13] (a) R. W. Adams, J. A. Aguilar, K. D. Atkinson, M. J. Cowley, P. I. P. Elliott, S. B. Duckett, G. G. R. Green, I. G. Khazal, J. López-Serrano, D. C. Williamson, Science 2009, 323, 1708-1711; (b) P. J. Rayner, S. Duckett, Angewandte Chemie International Edition 2018, 57, 6742-6753.

[14] R. W. Adams, S. B. Duckett, R. A. Green, D. C. Williamson, G. G. R. Green, Journal of Chemical Physics 2009, 131, 194505.

[15] P. J. Rayner, M. J. Burns, A. M. Olaru, P. Norcott, M. Fekete, G. G. R. Green, L. A. R. Highton, R. E. Mewis, S. B. Duckett, Proceedings of the National Academy of Sciences of the United States of America 2017, 114, E3188-E3194

[16] (a) Z. Zhou, J. Yu, J. F. P. Colell, R. Laasner, A. Logan, D. A. Barskiy, R. V. Shchepin, E. Y. Chekmenev, V. Blum, W. S. Warren, T. Theis, The Journal of Physical Chemistry Letters 2017, 8, 3008-3014; (b) S. S. Roy, P. Norcott, P. J. Rayner, G. G. R. Green, S. B. Duckett, Chemistry - A European Journal 2017, 23, 10496-10500.

[17] (a) M. L. Truong, T. Theis, A. M. Coffey, R. V. Shchepin, K. W. Waddell, F. Shi, B. M. Goodson, W. S. Warren, E. Y. Chekmenev, The Journal of Physical Chemistry C 2015, 119, 8786-8797; (b) T. Theis, G. X. Ortiz, A. W. J. Logan, K. E. Claytor, Y. Feng, W. P. Huhn, V. Blum, S. J. Malcolmson, E. Y. Chekmenev, Q. Wang, W. S. Warren, Science Advances 2016, 2, e1501438.

[18] (a) V. V. Zhivonitko, I. V. Skovpin, I. V. Koptyug, Chemical Communications 2015, 51, 2506-2509; (b) M. J. Burns, P. J. Rayner, G. G. R. Green, L. A. R. Highton, R. E. Mewis, S. B. Duckett, The Journal of Physical Chemistry B 2015, 119, 5020-5027; (c) A. M. Olaru, A. Burt, P. J. Rayner, S. J. Hart, A. C. Whitwood, G. G. R. Green, S. B. Duckett, Chemical Communications 2016, 52, 14482-14485.

[19] (a) R. W. Adams, S. B. Duckett, R. A. Green, D. C. Williamson, G. G. R. Green, Journal of Chemical Physics 2009, 131; (b) N. Eshuis, R. Aspers, B. J. A. van Weerdenburg, M. C. Feiters, F. Rutjes, S. S. Wijmenga, M. Tessari, Journal of Magnetic Resonance 2016, 265, 59-66.

[20] (a) K. D. Atkinson, M. J. Cowley, S. B. Duckett, P. I. P. Elliott, G. G. R. Green, J. López-Serrano, I. G. Khazal, A. C. Whitwood, Inorganic Chemistry 2009, 48, 663-670; (b) A. N. Pravdivtsev, A. V. Yurkovskaya, H.-M. Vieth, K. L. Ivanov, The Journal of Physical Chemistry B 2015, 119, 13619-13629; (c) T. Theis, M. Truong, A. M. Coffey, E. Y. Chekmenev, W. S. Warren, Journal of Magnetic Resonance 2014, 248, 23-26; (d) S. S. Roy, G. Stevanato, P. J. Rayner, S. B. Duckett, Journal of Magnetic Resonance 2017, 285, 55-60.

[21] M. J. Cowley, R. W. Adams, K. D. Atkinson, M. C. R. Cockett, S. B. Duckett, G. G. R. Green, J. A. B. Lohman, R. Kerssebaum, D. Kilgour, R. E. Mewis, Journal of the American Chemical Society 2011, 133, 61346137.

[22] (a) B. J. A. van Weerdenburg, S. Gloggler, N. Eshuis, A. H. J. Engwerda, J. M. M. Smits, R. de Gelder, S. Appelt, S. S. Wymenga, M. Tessari, M. C. Feiters, B. Blumich, F. P. J. T. Rutjes, Chemical Communications 2013, 49, 7388-7390; (b) L. S. Lloyd, A. Asghar, M. J. Burns, A. Charlton, S. Coombes, M. J. Cowley, G. J. Dear, S. B. Duckett, G. R. Genov, G. G. R. Green, L. A. R. Highton, A. J. J. Hooper, M. Khan, I. G. Khazal, R.
J. Lewis, R. E. Mewis, A. D. Roberts, A. J. Ruddlesden, Catalysis Science \& Technology 2014, 4, 3544-3554.

[23] (a) M. Fekete, C. Gibard, G. J. Dear, G. G. R. Green, A. J. J. Hooper, A D. Roberts, F. Cisnetti, S. B. Duckett, Dalton Transactions 2015, 44 7870-7880; (b) F. Shi, P. He, Q. A. Best, K. Groome, M. L. Truong, A. M. Coffey, G. Zimay, R. V. Shchepin, K. W. Waddell, E. Y. Chekmenev, B. M. Goodson, The Journal of Physical Chemistry C 2016, 120, 1214912156; (c) P. Rovedo, S. Knecht, T. Bäumlisberger, A. L. Cremer, S. B Duckett, R. E. Mewis, G. G. R. Green, M. Burns, P. J. Rayner, D. Leibfritz, J. G. Korvink, J. Hennig, G. Pütz, D. von Elverfeldt, J.-B. Hövener, The Journal of Physical Chemistry B 2016, 120, 5670-5677; (d) P. Spanning, I. Reile, M. Emondts, P. P. M. Schleker, N. K. J. Hermkens, N. G. J. van der Zwaluw, B. J. A. van Weerdenburg, P. Tinnemans, M. Tessari, B. Blümich, F. P. J. T. Rutjes, M. C. Feiters, Chemistry - A European Journal 2016, 22, 9277-9282; (e) J. F. P. Colell, M. Emondts, A. W. J. Logan, K. Shen, J. Bae, R. V. Shchepin, G. X. Ortiz, P. Spannring, Q. Wang, S. J. Malcolmson, E. Y. Chekmenev, M. C. Feiters, F. P. J. T. Rutjes, B. Blümich, T. Theis, W. S. Warren, Journal of the American Chemical Society 2017, 139, 7761-7767.

[24] F. Shi, A. M. Coffey, K. W. Waddell, E. Y. Chekmenev, B. M. Goodson Angewandte Chemie International Edition 2014, 53, 7495-7498.

[25] (a) M. Fekete, O. Bayfield, S. B. Duckett, S. Hart, R. E. Mewis, N. Pridmore, P. J. Rayner, A. Whitwood, Inorganic Chemistry 2013, 52, 13453-13461; (b) P. J. Rayner, M. J. Burns, A. M. Olaru, P. Norcott, M. Fekete, G. G. R. Green, L. A. R. Highton, R. E. Mewis, S. B. Duckett Proceedings of the National Academy of Sciences 2017, 114, E3188E3194; (c) P. Norcott, P. J. Rayner, G. G. R. Green, S. Duckett Chemistry - A European Journal 2017, 23, 16990-16997.

[26] A. Manoharan, P. J. Rayner, W. Iali, M. J. Burns, V. H. Perry, S. B. Duckett, ChemMedChem 2018, 13, 352-359.

[27] W. Iali, A. M. Olaru, G. G. R. Green, S. B. Duckett, Chemistry - A European Journal 2017, 23, 10491-10495.

[28] (a) D. A. Barskiy, L. A. Ke, X. Li, V. Stevenson, N. Widarman, H. Zhang, A. Truxal, A. Pines, The Journal of Physical Chemistry Letters 2018, 9, 2721-2724; (b) B. E. Kidd, J. L. Gesiorski, M. E. Gemeinhardt, R. V. Shchepin, K. V. Kovtunov, I. V. Koptyug, E. Y. Chekmenev, B. M Goodson, The Journal of Physical Chemistry C 2018, 122, 16848-16852.

[29] M. Knip, I. F. Douek, W. P. T. Moore, H. A. Gillmor, A. E. M. McLean, P. J. Bingley, E. A. M. Gale, f. t. E. Group, Diabetologia 2000, 43, 13371345

[30] P. A. Williams, J. M. Harder, B. H. Cardozo, N. E. Foxworth, S. W. M. John, Communicative \& Integrative Biology 2018, 11, e1356956. in Doc. Ref. EMEA/CHMP/SWP/4446/2000, 2008.

[32] W. Liu, R. Gust, Chemical Society Reviews 2013, 42, 755-773.

[33] (a) C. H. Leung, H. J. Zhong, D. S. H. Chan, D. L. Ma, Coordination Chemistry Reviews 2013, 257, 1764-1776; (b) D. L. Ma, D. S. H. Chan, C. H. Leung, Accounts of Chemical Research 2014, 47, 3614-3631.

[34] (a) A. Kascatan-Nebioglu, M. J. Panzner, J. C. Garrison, C. A. Tessier, W. J. Youngs, Organometallics 2004, 23, 1928-1931; (b) J. Schutz, W. A. Herrmann, J Organomet Chem 2004, 689, 2995-2999; (c) A Kascatan-Nebioglu, M. J. Panzner, C. A. Tessier, C. L. Cannon, W. J. Youngs, Coordination Chemistry Reviews 2007, 251, 884-895; (d) V. R Landaeta, R. E. Rodríguez-Lugo, E. N. Rodríguez-Arias, D. S. CollGómez, T. González, Transition Metal Chemistry 2010, 35, 165-175; (e) L. Stefan, B. Bertrand, P. Richard, P. Le Gendre, F. Denat, M. Picquet, D. Monchaud, ChemBioChem 2012, 13, 1905-1912; (f) T. Zou, C. T. Lum, S. S.-Y. Chui, C.-M. Che, Angewandte Chemie International Edition 2013, 52, 2930-2933; (g) B. Bertrand, L. Stefan, M. Pirrotta, D. Monchaud, E. Bodio, P. Richard, P. Le Gendre, E. Warmerdam, M. H. de Jager, G. M. M. Groothuis, M. Picquet, A. Casini, Inorganic Chemistry 2014, 53, 22962303.

[35] P. Talik, J. Krzek, R. J. Ekiert, Separation \& Purification Reviews 2012, 41, 1-61.

[36] (a) D. M. L. Goodgame, P. B. Hayman, R. T. Riley, D. J. Williams, Inorg Chim a-Bioinor 1984, 91, 89-93; (b) J. R. Lusty, P. F. Lee, Inorg Chim aBioinor 1984, 91, L47-L49.

[37] R. Pettinari, F. Condello, F. Marchetti, C. Pettinari, P. Smoleński, T. Riedel, R. Scopelliti, P. J. Dyson, European Journal of Inorganic Chemistry 2017, 2017, 2905-2910. 
[38] H. Zeng, J. Xu, J. Gillen, M. T. McMahon, D. Artemov, J.-M. Tyburn, J. A. B. Lohman, R. E. Mewis, K. D. Atkinson, G. G. R. Green, S. B. Duckett, P. C. M. van Zijl, Journal of Magnetic Resonance 2013, 237, 73-78.

[39] H. Zeng, J. Xu, M. T. McMahon, J. A. B. Lohman, P. C. M. van Zijl, Journal of Magnetic Resonance 2014, 246, 119-121.

[40] L. D. Vazquez-Serrano, B. T. Owens, J. M. Buriak, Chemical Communications 2002, 2518-2519.

[41] T. Mosmann, J Immunol Methods 1983, 65, 55-63. 
Entry for the Table of Contents (Please choose one layout)

Layout 1:

\section{ARTICLE}

Text for Table of Contents

Layout 2:

\section{ARTICLE}

Author(s), Corresponding Author(s)*

Page No. - Page No.

Title

((Insert TOC Graphic here))

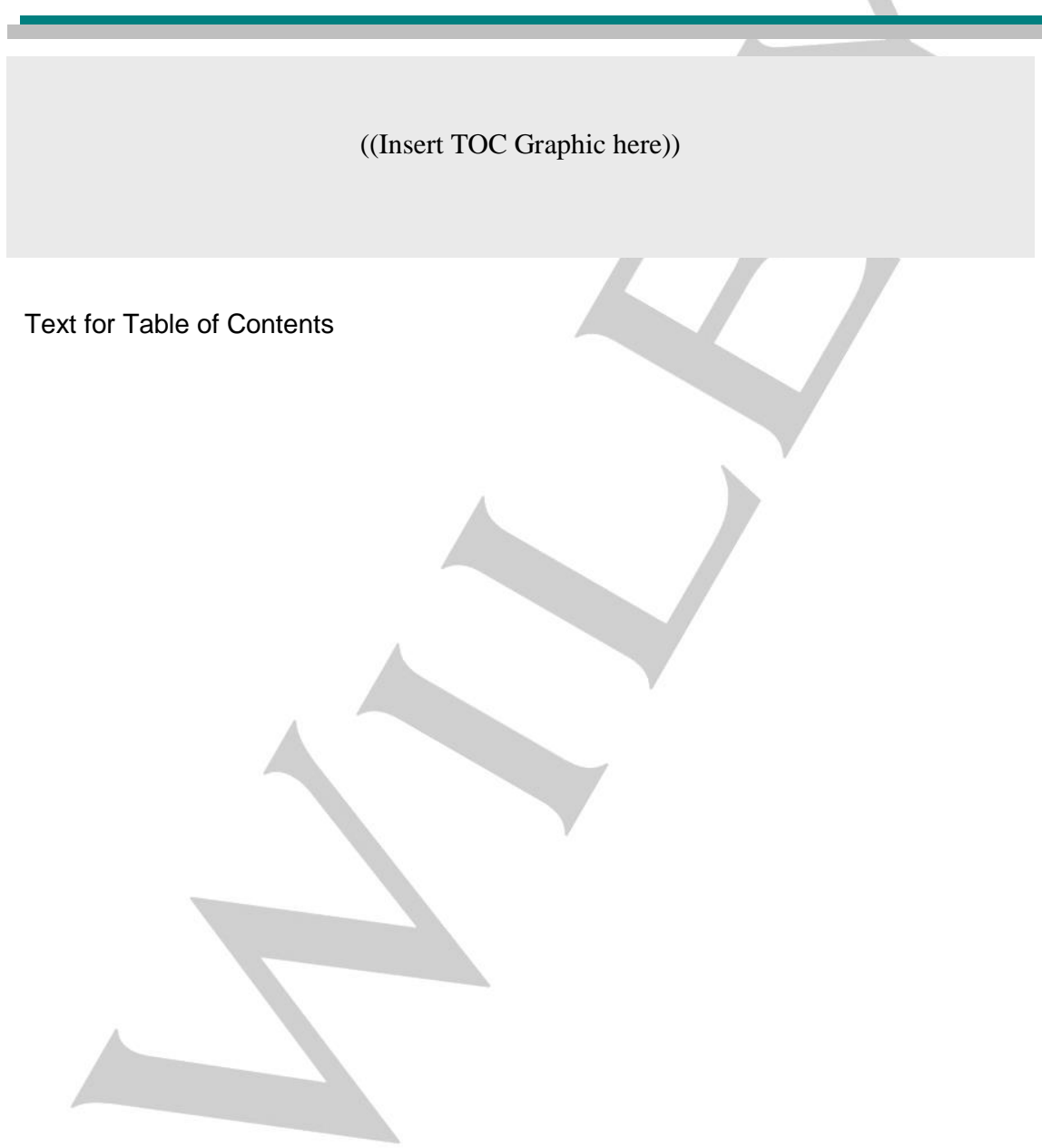

Author(s), Corresponding Author(s)*

Page No. - Page No.

Title 